\title{
ANÁLISE DA FORMAÇÃO E DA CULTURA ORGANIZACIONAL EM SINDICATOS E SUAS PARTICULARIDADES
}

\author{
Ana Carolina Bendlin Gonzalez ${ }^{1}$
}

\section{RESUMO}

Este trabalho analisa a formação da cultura organizacional em sindicatos e suas particularidades. Aborda, inicialmente, as características dessas entidades no Brasil e depois as relaciona à teoria da cultura organizacional com base principalmente na obra de Edgar Schein. Ao final, propõe uma reflexão a respeito da possibilidade de existência de duas culturas no ambiente do sindicato: a própria cultura da organização sindical, que agrega diretoria e funcionários da entidade, e a cultura profissional, mais abrangente, e que envolve os demais associados da instituição.

Palavras-chave: Cultura, Sindicatos, Cultura profissional, Cultura organizacional.

\begin{abstract}
The aim of this essay is to analyze the formation of the organizational culture of unions and its particularities. In the beginning of this text, we show some characteristics of these institutions in Brazil and we analyze it by using mainly Edgar Schein's studies. In the end, this essay claims the possibility of the existence of two cultures in the union ambience: the organization cultural of the union itself, which involves its staff; and the professional culture, which involves the whole institution.
\end{abstract}

Keywords: Culture, Unions, Professional culture, Organizational culture.

\section{INTRODUÇÃO}

Apesar de ser um tema de importância para o entendimento do funcionamento de empresas e outras instituições, somente nas últimas décadas os estudos sobre cultura organizacional têm ganhado força, principalmente a partir da década de 1980. Mesmo assim, muito é falado sobre a cultura organizacional em empresas, mas ainda existem lacunas em relação ao assunto quando se fala em cultura organizacional de outros tipos

\footnotetext{
${ }^{1}$ Especialista em Comunicação Empresarial e Institucional pela Universidade Tecnológica Federal do Paraná.
} 
de instituições, como grupos religiosos, escolas, cooperativas, associações em geral ou qualquer entidade pública ou privada cujos membros estejam unidos por um objetivo em comum.

O objetivo deste trabalho é analisar a questão da cultura organizacional em uma dessas instituições que não são necessariamente empresas, mas também possuem características que fazem com que tenham uma cultura organizacional a ser estudada. A instituição escolhida para análise é o sindicato, mas muitos dos conceitos que serão expostos nesse trabalho também podem ser utilizados para analisar essas outras entidades que possuem cultura organizacional e não podem ser enquadradas como empresas, principalmente aquelas que possuem caráter próximo ao dos sindicatos, como as federações e confederações.

Para que essa análise de toda a questão da cultura organizacional em sindicatos possa ser feita, mostrando inclusive essa possibilidade de existência de duas culturas em um mesmo ambiente, este trabalho terá como base os conceitos apresentados por Edgar Schein, que tem se dedicado ao estudo da cultura organizacional, em uma revisão de literatura.

Para entender melhor a relação dos sindicatos com os conceitos das teorias sobre cultura organizacional, é necessário abordar todos os aspectos referentes aos dois assuntos - as organizações sindicais e a cultura organizacional propriamente dita. Por isso, no início deste trabalho, será exposto um breve histórico da formação das organizações sindicais até o momento em que elas finalmente se estruturam e estabilizam, tomando a forma que apresentam nos dias de hoje. Também nesse segmento, serão apresentadas as características administrativas dos sindicatos, como eles se organizam e se compõem como instituição.

Já a sequência do trabalho será dedicada a uma exposição sobre os conceitos da teoria sobre cultura organizacional, principalmente sob a ótica de Edgar Schein. Primeiro, serão apresentados os conceitos básicos sobre o assunto e, depois, os níveis de cultura e como ela se desenvolve nas instituições. Por último, será feita a análise da questão da cultura organizacional nos sindicatos, relacionando os conceitos expostos no trabalho referente à obra do autor Edgar Schein e as características das entidades sindicais.

Todos esses conceitos culminam ainda em uma última análise, ainda mais 
importante, que encerra este trabalho e que diz respeito à possibilidade de existência de duas culturas organizacionais em uma mesma instituição: a cultura dos funcionários e diretoria do sindicato e a cultura dos associados ao sindicato, ou seja, os trabalhadores de uma mesma profissão que são filiados a uma determinada associação trabalhista.

\section{BREVE HISTÓRICO DA FORMAÇÃO DAS ORGANIZAÇÕES SINDICAIS}

Apesar de o processo de formação dos sindicatos no Brasil ter acontecido tardiamente, sua evolução aconteceu basicamente da mesma maneira como ocorrido em outros países. No entanto, por ter iniciado somente no século XIX, com características muito atrasadas em relação aos demais países, principalmente os europeus, o processo brasileiro de formação e evolução dos sindicatos aconteceu mais rapidamente. "Em nosso país, as primeiras organizações profissionais tiveram vida muito relativa, com o aspecto geral das corporações medievais, mas sem a pujança, verificando-se, especialmente no Rio de Janeiro, a reunião de trabalhadores do mesmo ofício em zonas ou ruas" (VIANNA, 1953, p. 16). A continuação desta história é descrita da seguinte forma:

\footnotetext{
No Brasil, particularmente na segunda metade do século XIX, os trabalhadores urbanos mais qualificados, em sua maioria exercendo ofícios artesanais, organizaram-se em sociedades de socorros mútuos, tendo em vista o fato de que a Constituição de 1824 impedia que fossem criadas quaisquer formas de organização sindical. E foi nas sociedades de socorros mútuos que os trabalhadores puderam buscar a solidariedade no caso de enfermidades, invalidez, desemprego, bem como defender os interesses de seu ofício (LAIMER, 2003, p. 20).
}

Já no século XX, houve a regulamentação da atividade sindical, em 1903, prevendo já a função de defesa dos interesses de seus associados e, em 1907, também das categorias profissionais (LAIMER, 2003, p. 21). Mas foi no ano de 1943 que a atividade sindical ganhou mais força e reconhecimento do governo federal, com a criação da Consolidação das Leis do Trabalho (CLT), documento com importância significativa por definir juridicamente, pela primeira vez, o que é um sindicato:

A definição fundamental da união sindical está formulado no Artigo 511 da CLT: "É lícita a associação, para fins de estudo, defesa e coordenação dos seus interesses econômicos ou profissionais, de todos os que, como empregadores, empregados, agentes ou trabalhadores autônomos, ou profissionais liberais, exerçam respectivamente a mesma atividade ou profissão ou atividades ou profissões similares ou conexas" (FÜTCHNER, 1980, p. 53). 
No entanto, as atividades sindicais no Brasil ainda foram interrompidas durante o período da Ditadura Militar, para retornarem com força total após a promulgação da Constituição de 1988. De qualquer forma, em todos os momentos em que as organizações sindicais puderam atuar no Brasil, elas sempre seguiram as características já citadas, que permeiam as atividades dessas agremiações no restante do mundo, como os motivos pelos quais os sindicatos existem - a defesa dos interesses de um grupo de profissionais —, as divisões por profissões e a administração separada em diretora e demais afiliados. Por fim, o processo de formação e evolução dos sindicatos no Brasil e no mundo pode ser resumido da seguinte forma:

De acordo com o exposto nessa breve abordagem histórica, constata-se que os sindicatos surgiram como um fenômeno sociológico, como uma necessidade dos que vendiam a força de trabalho. E as primeiras manifestações no Brasil acerca das organizações dos trabalhadores, foram as Corporações de Ofício que, com o tempo, cederam espaço aos sindicatos que, por sua vez, assumiram um papel de defesa dos interesses dos trabalhadores (LAIMER, 2003, p. 24).

\section{CARACTERÍSTICAS ADMINISTRATIVAS DAS ORGANIZAÇÕES SINDICAIS}

Após conhecer um pouco da história da formação e evolução dos sindicatos no Brasil e no mundo, antes de dar prosseguimento a este trabalho científico e analisar como se forma, desenvolve-se e se estrutura a cultura organizacional nessas agremiações, é necessário entender melhor suas características e sua estrutura, começando por uma definição do que é o sindicato: "É pessoa jurídica trabalhista, real e coletiva. Possui personalidade jurídica, e não se confunde com qualquer outra pessoa jurídica, civil ou comercial, embora se aproxime da cooperativa" (ROMITA, 1986, p. 121). Mas, acima de tudo, o sindicato é uma entidade privada, não pública, pois “a administração sindical não é exercida pelo Estado, mas por representantes diretos dos próprios associados, mediante eleição" (VIANNA, 1953, p. 117).

Pelo menos um terço desses associados deve pertencer a uma única categoria profissional, definida na fundação do sindicato: “A autonomia de organização é fixada no ato constitutivo do sindicato, quando os associados estabelecem a categoria que representarão. (...) E a amplitude da representação do sindicato dependerá do número de sócios que tiverem" (LAIMER, 2003, p. 41). Ainda existe a possibilidade de o sindicato representar empregados ou empregadores, conforme a escolha de seus afiliados. A partir 
da fundação do sindicato, os membros escolhem uma diretoria e decidem em assembleias os rumos da agremiação. Qualquer associado ao sindicato pode se candidatar à sua direção.

Ao contrário do número de associados do sindicato, que é ilimitado, essa diretoria, eleita pelos demais membros da agremiação, deve obedecer a uma quantidade pré-estabelecida. "A fim de evitar que os poderes se enfeixem em uma só pessoa ou que, pelo contrário, se dificulte a administração com um número elevado de dirigentes, a Consolidação (CLT) estabelece que os diretores serão 3, no mínimo, e 7 no máximo. A diretoria terá sua gestão financeira controlada por um Conselho Fiscal de 3 membros" (VIANNA, 1953, p. 63). Fütchner ainda completa: “Ambas as seções - diretoria e conselho fiscal - são eleitas por votação secreta, em assembleia geral, a cada dois anos. É permitida a reeleição" (FÜTCHNER, 1980, p. 56).

Os prazos devem ser respeitados para que haja transparência no processo de transição entre uma diretoria e outra, já que, apesar de ser uma entidade privada, o sindicato é regulamentado pelo poder público. "Meticulosa, a legislação fixa prazos certos para a realização dos pleitos, evitando que, por omissão, uma diretoria possa se eternizar, procrastinando a realização da assembleia eleitoral" (VIANNA, 1953, p. 59). Ele ainda explica que "as funções e poderes de cada diretor serão fixados no Estatuto da entidade ou, quando neste assim se dispuser, nos regimentos internos" (VIANNA, 1953, p. 63).

Além dos associados e dos membros de sua diretoria, os sindicatos ainda são compostos por um terceiro grupo de pessoas, os funcionários contratados para executar outras funções administrativas. Estes não exercem necessariamente a mesma profissão defendida pelo sindicato, mas estão unidos diretamente à diretoria por atuarem em funções essenciais para o andamento das agremiações, possibilitando que elas possam atingir seus objetivos de defender os interesses da categoria representada.

Sendo assim, pode-se dizer que a comunidade ligada a um sindicato é dividida em dois grupos, o dos associados, ligados à entidade pelos interesses em comum e pela contribuição sindical mensal, e outro, formado pela diretoria e pelos funcionários, unidos pelos objetivos de defender os interesses do primeiro. Apesar de aparentemente ligados pelos mesmos objetivos e interesses, existe uma separação clara entre os dois grupos, até mesmo física, já que o grupo da diretoria e dos funcionários tem um convívio maior na sede do sindicato, o que poderia causar a formação de duas culturas distintas. Essa 
hipótese será analisada mais a fundo na terceira parte deste trabalho científico. Mas, para que essa análise seja possível, o próximo segmento será dedicado exclusivamente à exposição dos conceitos de cultura organizacional, que servirão para contextualizar a principal análise deste trabalho.

\section{CONCEITOS SOBRE A FORMAÇÃO DA CULTURA ORGANIZACIONAL}

Cultura organizacional é uma característica pouco tangível; o entendimento dela parte da compreensão do próprio conceito de cultura:

\footnotetext{
Cada um de nós transporta consigo padrões de pensamento, de sentimentos e de ação potencial, que são o resultado de uma aprendizagem contínua. Uma boa parte foi adquirida no decurso da infância, período do desenvolvimento onde somos mais suscetíveis à aprendizagem e assimilação. Quando certos padrões de pensamento, sentimentos e comportamentos se instalam na mente de cada um, torna-se necessário desaprender, antes de aprender algo diferente, e desaprender é mais difícil que aprender pela primeira vez (HOFSTEDE, 2003, p. 18).
}

Já para o escritor Edgar Schein, a cultura é "um fenômeno dinâmico que nos cerca em todas as horas, sendo criada por nossas interações com outros e moldada por comportamento de liderança, e um conjunto de estruturas, rotinas, regras e normas que orientam e restringem o comportamento" (SCHEIN, 2009, p. 9). O autor ainda ressalta essa semelhança entre o processo de formação da índole de uma pessoa e o processo de formação da cultura nas organizações, ao dizer que "a cultura está para um grupo como que a personalidade ou caráter está para um indivíduo" (SCHEIN, 2009, p. 8).

O autor ainda explica essa relação de indivíduos e grupos, ao afirmar que "à medida que nossa personalidade e caráter orientam e restringem nosso comportamento, a cultura guia e restringe o comportamento dos membros de um grupo, mediante normas compartilhadas e assumidas nesse grupo" (SCHEIN, 2009, p. 8).

Por se tratarem de grupos, formados por indivíduos, as organizações também apresentam um processo de formação de cultura. Hofstede vê essa cultura como " $a$ programação coletiva da mente que distingue os membros de uma organização dos de outra" (HOFSTEDE, 2003, p. 210, grifos do autor). Já para Schein, "qualquer unidade social que tenha algum tipo de história terá desenvolvido uma cultura" (SCHEIN, 2009, p. 11), ou seja, "a cultura de um grupo pode ser definida como um padrão de suposições básicas compartilhadas, que foi aprendido por um grupo à medida que solucionava seus 
problemas de adaptação externa e de integração interna" (SCHEIN, 2009, p. 16). A partir desta declaração, pode-se perceber que a cultura é algo abstrato, que envolve os integrantes de um grupo, ou seja, de uma organização, e permeia as ações de determinada empresa ou entidade durante toda a sua existência, desde sua criação, como explica o próprio Schein:

Cultura é um fenômeno dinâmico que nos cerca todas as horas, sendo constantemente desempenhada e criada por nossas interações com outros e moldada por comportamento de liderança e um conjunto de estruturas, rotinas, regras e normas que orientam e restringem o comportamento (SCHEIN, 2009, p. 1).

Portanto, a cultura é incorporada pelos integrantes da organização como forma de se integrarem ao grupo e, consequentemente, terem condições de sobreviverem nesse ambiente, como também explica Schein:

\footnotetext{
A força e a estabilidade da cultura derivam do fato de ela estar baseada no grupo - de que o indivíduo assumirá certas suposições básicas para ratificar sua filiação ao grupo (...). Esse processo de tentar ser aceito por grupos de filiação ou de referência é inconsciente e, em virtude desse fato, muito poderoso (SCHEIN, 2009, p. 57).
}

Mas, se os integrantes da organização incorporam uma cultura já existente a seus hábitos para se sentirem parte do grupo, de onde surge essa cultura primeiramente? A resposta do autor é de que "as culturas iniciam-se com líderes que impõem seus próprios valores e suposições a um grupo" (SCHEIN, 2009, p. 1). Esses pensamentos podem dar início à formação da cultura, "que definirá às próximas gerações de membros que tipos de liderança são aceitáveis" (SCHEIN, 2009, p. 2).

Dado o contexto acerca da formação e do desenvolvimento da cultura organizacional em empresas ou outras instituições, Schein ainda define algumas características essenciais que a tal cultura apresenta. As características sugeridas pelo estudioso seriam estabilidade estrutural — "cultura implica algum nível de estabilidade estrutural no grupo; quando dizemos que algo é 'cultural', afirmamos que não é apenas compartilhado, mas também estável, porque define o grupo" -, profundidade - "cultura é a parte mais profunda, frequentemente inconsciente, de um grupo; assim, é menos tangível e menos visível do que as outras partes" -, extensão - "a cultura é universal; influencia todos os aspectos de como uma organização lida com sua tarefa principal, seus 
vários ambientes e suas operações internas" - e padronização ou interação - "de algum modo, cultura implica que rituais, clima, valores e comportamentos vinculam-se em um todo coerente; essa padronização ou interação é a essência do que entendemos por 'cultura"” (SCHEIN, 2009, p. 13-14).

\title{
3.1. OS NÍVEIS DE CULTURA
}

Para entender o fenômeno da cultura organizacional, é preciso compreender os níveis da cultura, suas manifestações e sua profundidade, como o próprio Schein salienta:

\begin{abstract}
Parte da confusão em torno da definição do que cultura realmente é resulta de não diferenciar os níveis em que ela se manifesta. Esses níveis variam de manifestações abertas muito tangíveis quer se podem ver e sentir, às suposições básicas, inconscientes e profundamente inseridas que defino como essência da cultura. Entre essas camadas estão várias crenças, valores, normas e regras de comportamento assumidos que os membros da cultura usam como meio de retratá-la a si e aos outros (SCHEIN, 2009, p. 23).
\end{abstract}

Para o autor, o nível mais superficial seria o dos artefatos, os elementos visíveis e possíveis de serem observados. Em seguida, viriam as crenças e os valores, aquilo que os integrantes da organização acreditam intuitivamente e que, junto com os artefatos, são as manifestações da cultura. Por último, estariam as suposições fundamentais básicas, as ideias assumidas como verdadeiras e, portanto, inquestionáveis. "Este grau de consenso resulta de sucesso repetido em implementar certas crenças e valores, como anteriormente descrito (...). As suposições básicas (...) tendem a não ser confrontadas ou debatidas e por isso são extremamente difíceis de mudar" (SCHEIN, 2009, p. 28-29). Ele ainda resume essa divisão em níveis da seguinte maneira: "Embora a essência da cultura de um grupo seja seu padrão de suposições básicas, compartilhadas e assumidas como verdadeiras, ela se manifestará no nível dos artefatos observáveis e das crenças e valores assumidos e compartilhados" (SCHEIN, 2009, p. 33).

Já Hofstede, apesar de ter uma forma muito parecida de pensar em relação a Schein, apresenta, em seus estudos, uma nomenclatura diferente para descrever os níveis da cultura. Para o autor, "de entre os muitos termos usados para descrever as manifestações da cultura, podemos reter quatro que cobrem a totalidade do conceito de 
forma minuciosa: símbolos, heróis, rituais e valores" (HOFSTEDE, 2003, p. 22). Nesta divisão, os símbolos seriam os elementos mais superficiais, juntamente com os heróis e os rituais, que, por serem visíveis ao observador externo, podem ser agrupados em outro subgrupo, chamado de práticas, ou seja, estes seriam as formas de manifestação da cultura.

Por último, o autor ainda elenca mais um nível, o dos valores, que seria o mais profundo e não tangível. "Podemos definir um valor como a tendência para se preferir um certo estado de coisas face a outro. É um sentimento orientado, com um lado positivo e outro negativo" (HOFSTEDE, 2003, p. 23). Apesar de discordarem em alguns pontos, ambos os estudiosos concordam que a cultura organizacional é dividida em níveis mais superficiais e outros mais profundos.

Entender essa divisão da cultura em níveis é essencial para compreender melhor como ela é forma e se desenvolve nos grupos, independente de que tipo de instituição eles formem. A partir dos conceitos expostos, é possível seguir adiante e chegar ao objeto principal de estudo deste trabalho, que é a análise da cultura organizacional em sindicatos.

\section{BREVE ANÁliSE SOBRE AS PARTICULARIDADES DA CULTURA ORGANIZACIONAL NOS SINDICATOS}

De acordo com Schein, "as organizações são o resultado de pessoas que trabalham juntas com um propósito comum" (SCHEIN, 2009, p. 179). Portanto, não são somente as empresas que podem ser consideradas organizações. Grupos religiosos, cooperativas e associações em geral, incluindo os sindicatos, podem ser chamados de organizações e, portanto, assim como as empresas, possuem uma determinada cultura organizacional. O próprio Schein esclarece essa questão ao dizer que "qualquer unidade social que tenha algum tipo de história compartilhada terá desenvolvido uma cultura" (SCHEIN, 2009, p. 11). Ele mesmo completa sua própria definição ao dizer que "sem um grupo não pode haver cultura e sem suposições compartilhadas, sem algum grau mínimo de cultura, estamos na verdade falando de um agregado de pessoas, não de um grupo" (SCHEIN, 2009, p. 82).

Esse último grupo, o dos sindicatos, foi o escolhido para ser objeto de estudo 
neste trabalho, como já foi comentado anteriormente. Se comparados com as empresas, os sindicatos possuem uma cultura organizacional um tanto quanto diferente, mas peculiar devido ao fato de ter algumas características muito diferentes, entre elas, a formação de dois grupos distintos de comunidades vinculadas à instituição, o grupo dos associados e o grupo formado pela diretoria e pelos funcionários da entidade, como também já foi explicado no primeiro capítulo deste trabalho e que será retomado mais adiante.

Para entender melhor como se dá o processo de formação da cultura organizacional nos sindicatos, é preciso retomar os ensinamentos de Schein, que explica como acontece esse processo nas organizações de uma forma geral:

Em grupos mais formais, um indivíduo cria o grupo ou torna-se seu líder. Pode ser um empreendedor que inicia uma nova empresa, um religioso que converte um seguidor, um líder político que cria um novo partido, um professor que inicia uma nova classe, ou um gerente que assume um novo departamento de uma organização. $\mathrm{O}$ fundador individual - seja um empreendedor ou apenas o iniciador de um grupo - terá certas visões, metas, crenças, valores e suposições pessoais sobre como as coisas devem ser. Inicialmente, imporá isso ao grupo e/ou membros selecionados na base de sua similaridade de pensamentos e valores. (...) Podemos pensar nessa imposição como ato principal de liderança, mas ela, automaticamente, não produz cultura. Tudo que produz é confiança nos seguidores a fazer o que líder lhes pede. Apenas se o comportamento resultante levar ao "sucesso" - no sentido de que o grupo realiza sua tarefa e os membros sentem-se bem sobre seus relacionamentos mútuos - as crenças e os valores do fundador serão confirmados e reforçados e, mais importante, passarão a ser reconhecidos como compartilhados. O que era originalmente a visão individual de mundo do fundador leva à ação compartilhada que, se bemsucedida, conduz a um reconhecimento compartilhado de que o fundador “estava certo". Então, o grupo agirá novamente sob essas crenças e valores e, se continuar bem-sucedido, finalmente concluirá que agora tem a forma "correta" de pensar, sentir e agir (SCHEIN, 2009, p. 15).

Levando em consideração os pensamentos do autor expostos, a hipótese que mais se aproxima dos sindicatos citados por ele é a da formação de um partido. Assim como os partidos, a questão da cultura organizacional nos sindicatos não é nada simples, pois existe uma particularidade, a mudança constante, pois a cada dois ou três anos, a diretoria passa por um processo de eleição, havendo a possibilidade de troca completa ou parcial de seus integrantes:

Os motivos de qualquer mudança em uma organização podem estar dentro da própria organização ou no ambiente onde ela está inserida, ou a combinação de ambos. Em alguns setores, como o político, onde as mudanças têm períodos certos para ocorrer, geralmente não são somente os objetivos que mudam. Troca-se primeiramente os sete cargos mais altos e esse processo muitas vezes gera insegurança pessoal e profissional nos funcionários. Em uma instituição sindical, a mudança dos cargos de dirigentes acompanha o setor político: em 
um espaço de tempo pré-determinado pelo estatuto, muda-se a presidência e seus diretores, estes por sua vez, trocam os cargos de confiança o que causa reflexo direto nos cargos de gerencia e no desempenho profissional do corpo de funcionários (QUEIROGA, 2009).

Sendo assim, nota-se que, apesar de existir um fundador ou um grupo de fundadores na história de cada sindicato, essas organizações não possuem um líder fixo, que esteja à frente da organização por muito tempo, ainda mais que, conforme descrito anteriormente, a diretoria dos sindicatos é formada por um grupo formado por três a sete pessoas para que o poder não se concentre em um único indivíduo ou se disperse em um grupo com muitas pessoas. Por isso, a transmissão da cultura para novos integrantes depende bastante do envolvimento dos membros de sua comunidade. Outra passagem de Schein ajuda a elucidar esse processo:

\begin{abstract}
A liderança passa a ser vista como um conjunto de atividades compartilhadas em vez de ser a característica de uma única pessoa, e surge um senso de propriedade dos resultados do grupo (...). O insight de que o líder não é onisciente ou onipresente dá aos membros um senso de alívio. (...) Há um sentimento de prazer ao reconhecer que todos do grupo exercem um papel e podem contribuir com a liderança; isso, por sua vez, fortalece o próprio sentimento de grupo. Nesse ponto, é comum os membros do grupo assumirem alguma ação conjunta para provar a si próprios que podem fazer algo, e ficam eufóricos pelo sucesso alcançado (SCHEIN, 2009, p. 69-70).
\end{abstract}

Portanto, não basta que a cultura seja criada, deve haver continuidade. É necessário que a comunidade ligada à organização se envolva e compartilhe aquelas suposições básicas, assumindo-as como verdadeiras. Assim, mesmo com mudanças frequentes na diretoria, a cultura sobrevive, pois "se um grupo trabalha com sucesso, inevitavelmente, reforçará suas próprias suposições e seu ambiente, fortalecendo assim qualquer cultura que tenha desenvolvido" (SCHEIN, 2009, p. 76). Isso porque se os membros do grupo estão envolvidos com a cultura daquela instituição, eles passaram os preceitos dessa cultura para os novos integrantes, mesmo que estes não sejam tão próximos ideologicamente, pois, apesar de novos na diretoria, tiveram contato anterior com a cultura por serem associados. Essas suposições compartilhadas se enraízam no grupo, que passa a defendê-las e não questioná-las, o que une o grupo e serve como identidade entre seus membros.

No entanto, esses momentos de transição podem ser um tanto quanto traumáticos e tumultuados caso não haja esse acompanhamento da diretoria anterior em relação à nova. De acordo com Schein, "as mentes humanas necessitam de estabilidade 
cognitiva; assim, qualquer desafio ou questionamento de uma suposição básica despertará ansiedade e defensividade" (SCHEIN, 2009, p. 30). O autor ainda completa o pensamento, ao dizer que "as suposições básicas compartilhadas que formam a cultura de um grupo podem ser imaginadas como mecanismos de defesa cognitivos e psicológicos que permitem ao grupo continuar a funcionar" (SCHEIN, 2009, p. 30). Adriana Queiroga explica como acontece esse processo nas organizações sindicais:

\begin{abstract}
A princípio, percebe-se que o processo de mudança nas instituições tem sido feito normalmente sem uma ampla discussão, participação ou conscientização dos seus trabalhadores. (...) Nos órgãos sindicais essa situação mostra-se mais grave, pois os funcionários recebem as novas diretrizes de forma arbitrária, muitas vezes por papeletas, ordens de serviço, portarias, sem que tenham tido a oportunidade de conhecimento ou manifestação prévia. Ao se promoverem mudanças organizacionais significativas nas organizações sindicais, a falta de inclusão do funcionário nesse processo pode gerar muitas dúvidas, temores e desequilíbrio. Isso pode ser fruto de uma falha no planejamento estratégico, resultado de problemas de comunicação, falta de informação ou pode tratar de descaso com o sujeito que faz parte dessa organização, criando um clima de desconfiança do funcionário para com o sindicato e um clima organizacional desfavorável dentro dele (QUEIROGA, 2009).
\end{abstract}

Nesses momentos de transição, existe dúvida em como será o futuro da instituição com novos dirigentes. De acordo com a autora, “observam-se os seguintes questionamentos: Como será agora? O que restou de nossa cultura com essa nova gestão? Posso confiar nessa nova diretoria, formada por quem não conheço?” (QUEIROGA, 2009). Mas existem algumas ações que podem ser tomadas para que a cultura seja transmitida com êxito, sem que a insegurança e a desconfiança prejudiquem o andamento das atividades do sindicato. Uma dessas estratégias seria a criação de comissões:

Há uma grande conveniência em criar no sindicato várias Comissões especiais. (...) É muito conveniente integrá-las com ex-diretores, que já conhecem os problemas do sindicato. (...) Haverá assim uma continuidade de orientação na vida sindical, evitando-se que, à mudança de cada diretoria, sejam modificados, muitas vezes com prejuízo para a classe, os serviços existentes (VIANNA, 1953, p. 65-66).

Isso vale para a transição da diretoria, mas os funcionários do sindicato também precisam de orientações. Nesse sentido, é necessário ter um planejamento, como ressalta Adriana Queiroga, quando diz que "Devido a trocas constantes de gestão na área sindical, ter um planejamento torna-se fundamental para que os envolvidos sintam-se 
seguros durante as mudanças na organização, e se sintam comprometidos com os dirigentes e seus interesses, e para que se possa assim garantir a continuidade dos objetivos estratégicos definidos em planos anteriores" (QUEIROGA, 2009).

Esse planejamento torna-se imprescindível para evitar que as mudanças provocadas pela troca da diretoria não criem um ambiente de insegurança entre os funcionários e até mesmo entre os associados, pois se considerarmos que a cultura nesse nível é como o DNA do grupo, como propõe Schein, "se uma nova aprendizagem ou crescimento forem necessários, os genes têm de estar lá para tornar tal crescimento possível, e o sistema autoimunológico precisa ser neutralizado para sustentar o novo crescimento" (SCHEIN, 2009, p. 30). No entanto, até que as mudanças se estabeleçam, esse ambiente de insegurança pode até mesmo prejudicar as ações da nova diretoria, pois “este clima representa um grande entrave ao trabalho do gestor, já que ele não pode contar com um nível satisfatório de comprometimento da equipe diante do processo de mudança" (QUEIROGA, 2009). Essas características apresentadas até o momento são apenas algumas das particularidades da cultura organizacional nos sindicatos. No entanto, a principal delas, que faz com que essas entidades sejam muito diferentes das empresas, será exposta adiante, pois merece um tópico à parte. Trata-se da formação de duas culturas coexistentes pela formação de duas comunidades ligadas aos sindicatos, como dito anteriormente. Por ser ainda mais complexa, esta característica deve ser estudada em separado.

\subsection{CULTURA ORGANIZACIONAL X CULTURA PROFISSIONAL}

A existência de forma simultânea de duas culturas distintas em um mesmo ambiente de uma organização sindical será o assunto aprofundado neste último tópico deste terceiro e último capítulo. Existem duas comunidades ligadas a quaisquer sindicatos, uma formada pela diretoria e pelos funcionários da instituição e outra pelos associados e outra. Esses dois grupos podem ser divididos desta maneira devido à diferença de percepções.

O primeiro, por trabalhar diariamente integrado aos objetivos do sindicato, acaba adquirindo sua cultura. Já o segundo, apesar de estar vinculado à entidade por meio da contribuição sindical, conta com ela apenas para defender seus interesses e não está envolvida nos processos rotineiros relacionados ao cotidiano da instituição. Isso acontece 
por diversos fatores.

Um deles é a não representatividade da diretoria. Como muitas vezes acontece de nem sempre todos os filiados ao sindicato votarem, a diretoria acaba não representando de fato a sua maioria, o que gera descontentamento, ou seja, existe parte dos associados não concorda com aquele grupo eleito para formar a diretoria e não sente que ele será capaz de defender seus interesses. Esse fenômeno pode ser entendido se forem levadas em consideração algumas definições a respeito da identidade de um grupo e se sua integração interna:

\begin{abstract}
Se um grupo for criado para funcionar e desenvolver, uma das áreas mais importantes de claro consenso é a percepção de quem faz parte do novo grupo e de quem está fora (ou não faz parte) e os critérios pelos quais as decisões de inclusão são tomadas. (...) No início, os critérios de inclusão são frequentemente estabelecidos pelo líder ou fundador. Porém, assim que os membros do grupo interagem, esses critérios são testados e surge um consenso em torno dos critérios que sobrevivem ao teste. Em uma nova empresa, há, com frequência, debate intenso sobre quem deve ser proprietário ou sócio, quem deve ter opções de compra de ações, quem deve ser contratado para as funções-chave ou para ser executivo, e quem deve ser demitido por não se ajustar à organização (SCHEIN, 2009, p. 108).
\end{abstract}

Outro fator que pode ser considerado determinante no processo de não envolvimento de parte dos associados de um sindicato à entidade é a interferência de outros interesses nas ações dos sindicatos, como a utilização da visibilidade de um cargo na diretoria da instituição para atingir objetivos pessoais, como uma carreira política, por exemplo. De acordo com Schein, uma das etapas para a adaptação externa e sobrevivência de um grupo é composta pelo estabelecimento de metas. "O grupo não pode atingir suas metas e atender à sua missão a menos que haja um claro consenso sobre os meios pelos quais essas metas serão atingidas" (SCHEIN, 2009, p. 88). Portanto, se as metas de um subgrupo e os meios para atingi-las acabam se sobrepondo às metas do grupo como um todo, assim como seu conceito de meio, há um desvirtuamento da função desse grupo. Isso tudo gera uma falta de identificação entre associados e sindicatos:

Uma função importante da cultura organizacional é distinguir uma organização de outras e de seu ambiente, proporcionando a esta uma identidade externa. De uma forma similar, cultura provê uma identidade para os membros da organização; ela os aloca em uma estrutura organizacional e ocupacional que é reconhecível por eles mesmos e pelos outros. Cultura também cria um senso de compromisso com uma entidade social maior do que o simples interesse 
pessoal (MAMEDE, grifos do autor).

Mas, se os associados ao sindicato não estão envolvidos com a cultura do sindicato, não as veem como suposições compartilhadas nas quais acreditam sem questionar, qual seria essa outra cultura coexistente no ambiente do sindicato? A possibilidade mais aceitável é de que esta seria a cultura profissional. O próprio Schein apresenta essa possibilidade em sua obra, sugerindo que a formação da cultura nas profissões passa por um processo muito semelhante à formação da cultura nas organizações, com particularidades parecidas com as dos sindicatos, como a não existência de um líder que seja mais duradouro. $\mathrm{O}$ autor faz um breve aprofundamento da questão da cultura em relação às profissões, com a seguinte explicação:

Se uma profissão envolve intenso período de educação e aprendizagem, haverá
certamente uma aprendizagem compartilhada de atitudes, normas e valores que
por fim se tornarão suposições assumidas como verdadeiras pelos membros
dessas profissões. Assumiu-se que as crenças e valores aprendidos durante esse
tempo permaneceriam estáveis como suposições, muito embora uma pessoa
possa nem sempre pertencer a um grupo de colegas da mesma profissão. Mas
o reforço dessas suposições ocorre em reuniões profissionais e programas de
educação continuada eem virtude do fato de que a prática da profissão
frequentemente exige trabalho em equipe entre os vários membros que se
reforçam mutuamente. Uma razão por que muitas profissões confiam
fortemente na avaliação pelo grupo de colegas é que esse processo preserva e
protege a cultura da profissão (SCHEIN, 2009, p. 19).

Portanto, esse grupo formado pelos associados que não têm contato direto com a cultura organizacional estaria ligado apenas pela cultura profissional. É claro que mesmo os integrantes da diretoria do sindicato, fazendo parte da mesma profissão, também teriam a tal cultura profissional. Trata-se apenas de uma diferenciação da cultura dominante de cada grupo. Essa constatação ainda está de acordo com o pensamento de Hofstede, que defende que "cada indivíduo pertence a vários grupos ou categorias em simultâneo, sendo assim portador de níveis de programação mental diferentes, que correspondem a diferentes níveis de cultura" (HOFSTEDE, 2003, p. 25). Ou seja, uma mesma pessoa poderia estar vinculada à cultura de sua profissão e, ao mesmo tempo, à cultura do sindicato, com exceção dos funcionários da entidade, que podem ser de outras profissões. Essa vinculação a duas culturas não é necessariamente um problema, a não ser quando essas culturas se chocam, deixando o profissional em um dilema acerca das suposições básicas das duas, ficando em dúvida sobre qual será mais determinante para sua atividade profissional. Sendo assim, essa duplicidade de cultura faz parte da rotina de qualquer 
trabalhador que esteja ligado diretamente à diretoria do sindicato de sua categoria e ele deve aprender a conviver com esse fenômeno.

\section{CONSIDERAÇÕES FINAIS}

Foram expostos neste trabalho alguns elementos referentes à questão da cultura organizacional das entidades sindicais, mostrando suas principais características e peculiaridades, inclusive a possibilidade da formação de duas culturas distintas e coexistentes, como exposto no último segmento.

No entanto, somente acompanhando o cotidiano de um sindicato seria possível identificar de fato a existência dessas duas culturas citadas neste trabalho baseado em uma revisão de literatura sobre o assunto. O próprio autor utilizado como referência, Edgar Schein, afirma que "determinar quais conjuntos de suposições aplicamse a toda uma sociedade, a uma organização completa ou a um subgrupo de uma organização ou profissão é algo que deve ser feito empiricamente" (SCHEIN, 2009, p. 19). Portanto, para se ter uma conclusão definitiva sobre o assunto abordado neste trabalho científico, seria necessária uma complementação com um estudo empírico, ou seja, uma pesquisa de campo em uma dessas organizações, entidades sindicais.

Portanto, o assunto ainda pode ser aprofundado ainda mais, pois existem detalhes que fogem a um trabalho feito exclusivamente com revisão de literatura. De qualquer forma, este artigo cumpre seu objetivo ao fazer uma análise sobre o tema, servindo de base para estudos mais aprofundados, realizados empiricamente.

\section{REFERÊNCIAS}

FLEURY, Maria Tereza Leme. Cultura organizacional e estratégias de mudança: recolocando estas questões no cenário brasileiro atual. Revista de Administração, v. 26, n. 2. São Paulo, 1991. Disponível em: http://www.faccamp.br/apoio/Any/cultura_ organizacional.pdf. Acesso em 5 de dezembro de 2010.

FÜCHTNER, Hans. Os sindicatos brasileiros, organização e função política. Rio de Janeiro: Edições Graal, 1980.

HOFSTEDE, Geert. Culturas e organizações: compreender a nossa programação mental. Trad. Antonio Fidalgo. Lisboa: Silabo, 2003.

LAIMER, Adriano Guedes. O novo papel dos sindicatos. São Paulo: Editora LTr, 2003.

MAMEDE, Antônio Augusto do Canto. A influência da cultura organizacional nos processos de mudança. Disponível em: 
http://www.biblioteca.sebrae.com.br/bds/BDS.nsf/4AD4782E13B055CB03256EF6005 06F48/\$File/NT00090F7A.pdf. Acesso em 5 de dezembro de 2010.

QUEIROGA, Adriana. Gestão de mudança organizacional em uma instituição sindical. Monografia de conclusão do Curso Pós-Graduação Gestão Estratégica de Pessoas no Centro Universitário UMA. Belo Horizonte, 2009. Disponível em: http://www.jogart.com.br/moodle/file.php/1/ARTIGOS/CULTURA_E_MUDANCA_O RGANIZACIONAL/GESTAO_DA_MUDANCA_ORGANIZACIONAL.pdf. Acesso em 5 de dezembro de 2010.

ROMITA, Arion Sayão. Sindicalismo. São Paulo: Editora LTr, 1986.

SCHEIN, Edgar. Cultura organizacional e liderança. São Paulo: Editora Atlas, 2009.

VIANNA, Segadas. O sindicato no Brasil. Rio de Janeiro: Olímpica Editora, 1953. 